\title{
Effect of Limb Massage and Exercises on Phantom Limb Pain among
}

\section{Amputee Patients}

\author{
Nassim Samir Saker, Lecturer \\ Adult Nursing, Faculty of Nursing, Tishreen University, Syria
}

\begin{abstract}
Phantom limb pain is experienced when the brain sends pain signals to limbs that are not there. Ongoing military conflicts, motor vehicle crashes and machinery accidents can cause traumatic injuries requiring amputation. Regardless of the cause of the injury, traumatic amputations result in a complex pain management issues. In addition, the postamputation pain can influence patients' mobility, sleep, and overall quality of life, despite the abundance of literature on phantom limb pain; there remains no clear consensus on the mechanisms of the disorder and best method of management. Objective: Determine the effect of limb massage and range of motion exercises on phantom limb pain among amputee patients. Setting: The study was carried out in Tishreen University Hospital, Lattakia, Syria. Subjects: The study comprised 30 adult male patients with amputee limb (upper or lower) aged 20-60 years. Tools: Socio-demographic and Clinical Data Structured Interview Schedule and Leeds Assessment of Neuropathic Symptoms and Signs Pain Scale (S-LANSS). Results: Results of the present study revealed that the implemented range of motion exercises and limb massage improved significantly the patients' phantom limb pain, whereby the mean score percent changes after exercises and massage was $26 \pm 2.35$ percentage, and the LANSS mean score decreased from $14 \pm 2.569$ to $10 \pm 3.288$. A statistical significant relation was noted between LANSS mean score and injury site and injury duration $(P=0.056, P=0.049$ respectively). Conclusion: Range of motion exercises and limb massage improved pain level among amputee patients. Recommendations: Based on the results the researcher recommended incorporating non-pharmacological methods like limb range of motion exercises and residual limb massage to relieve phantom limb pain.
\end{abstract}

Keywords: Phantom limb pain, Exercises, Massage.

\section{Introduction}

Phantom limb pain is defined as sensation of pain originating from an area of body tissue that is not physically present, it is a common phenomenon, which affects around $60-80 \%$ of limb amputees. The onset of phantom limb pain ranges from hours to decades, and the frequency of episodes vary from every few days to several times each day. The length of episodes can range from less than 1 minute to continuous. Often amputees also describe an awareness of nonpainful phantom sensations such as shooting, squeezing, tingling, throbbing, stabbing, burning, cramping and itching or pins and needles originating from the absent $\operatorname{limb} b^{(1-3)}$.
Phantom sensations and pain reported following amputation of different body parts including the eyes, tongue, nose, breast, bowel, and bladder but the most common occurrence is following limb amputation. Patients with phantom pain report of two peak periods of onset, the first within a month and the second a year after amputation $^{(2,4)}$.

The heterogeneity of phantom limb pain is widely acknowledged, and it recognized that the disorder likely arises from multiple mechanisms. Some authors have argued for mechanism-based management of pain, although others have attempted to classify amputation pain according to severity and etiology. 
However, phantom limb pain remains a blanket term for pain in absent tissue, regardless of the qualities and theorized mechanisms of this pain. Nurses should obtain information about pain from the patient as part of their care plan and use the tools available in their clinical area ${ }^{(5-7)}$.

The complex etiology of phantom limb pain leads to a variety of problems, including the potential for underreporting of pain in suffering patients. In a survey of 2694 military veterans, only 54\% reporting phantom limb pain sought treatment from their health care provider, and only $19 \%$ of those patients were offered any treatment. A similar study conducted in England reported that only 72 of 526 phantom limb pain sufferers requested any treatment from their health care provider. In both surveys, individual patients reported being told that there was nothing their health care provider could do for their pain or that the pain should resolve on its own. Several patients stated that their health care providers avoided answering the questions or told them that the pain was only "in their head" These reports are not surprising, considering the lack of evidence from controlled, longterm studies with large sample sizes and adequate follow-up that show effective treatments for phantom limb pain ${ }^{(8-11)}$.

Phantom limb pain related to traumatic amputations will continue to be a problem for the military health care system and international medical community as well as negatively influencing amputees' quality of life. The disparity between what is known about the causes and treatments and current practice must be addressed to improve outcomes for patients who suffer from post-amputation pain. Health care providers must place a priority on continuing to assess pain issues throughout the continuum of care. Providers at every level of care should be informed about the multitude of treatment options that exist, and about emerging research, to ensure that patients receive the individualized pain management that they deserve ${ }^{(12-15)}$.
Despite the abundance of literature on phantom limb pain, there remains no clear consensus on the mechanisms of the disorder; phantom limb pain may be attributed to genetic make-up, memories, neuroma, spinal plasticity, and cortical remapping. A standard treatment for the disorder remains equally elusive. Treatments range from acupuncture to deep brain stimulation and include mirror/virtual reality therapies, mental imagery, transcutaneous nerve stimulation, deep brain, motor cortex, and spinal cord stimulation, and the pharmaceutical agents such as morphine, gabapentin, amitriptyline, calcitonin, ketamine. The divergence in theories on phantom limb pain stems in part from the heterogeneity of the disorder itself $^{(5,16,17)}$

The refractory nature of phantom limb pain to traditional medical and interventional therapies underscores the importance of developing complementary and alternative therapies includes psychological (guided imagery, hypnosis, biofeedback therapy), cognitive, and behavioral methods in addition to other complementary methods like acupressure acupuncture, chiropractic, massage ${ }^{(14)}$.

Nurses have an important role in managing pain control because they have more contact with patients who are experiencing pain than any other healthcare professional. Using pain assessment tools improves communication and makes it easier to select the appropriate treatment. Assessment should include an evidencebased tool that is appropriate to the individual's needs and health problem and should consider the physical, psychological, social and spiritual aspects of the pain experience; they should be aware about phantom limb pain and how it can differ from other types of pain to ensure all patients receive holistic care ${ }^{(15,16,18)}$. In this study we will try to explore nonpharmacological methods effectiveness on phantom limb pain. 


\section{Aim of the Study}

The aim of this study is to determine the effect of limb massage and range of motion exercises on phantom limb pain among amputee patients.

\section{Research Hypothesis:}

Patients with phantom limb pain after amputation who are exposed to limb massage and range of motion exercises will exhibit relief of phantom limb pain.

\section{Materials and Method}

\section{Materials}

Design: Quasi-experimental (pre-post test).

Setting: The study was carried out in Tishreen University Hospital, Lattakia, Syria.

Subjects: A convenient sample of 30 adult male patients with amputee limb (upper or lower) their age 20-60 years, able to move without assistance, mentally capable of understanding and performing instructions, and agree to participate in the study.

\section{Tools:}

Tool I: Socio-demographic and Clinical Data Structured Interview Schedule

It was designed by the researcher after thorough review of literature and included Socio-demographic characteristics of the patients such as age, social status, level of education, occupation. Health history: including cause, site, and intensity of injury, operation type and time, presence of other chronic diseases and physical limitation.

\section{Tool II: Leeds Assessment of} Neuropathic Symptoms and Signs Pain Scale (S-LANSS)

The LANSS is a simple and valid 7-item tool for identifying patients whose pain dominated by neuropathic mechanisms; it has been tested in a number of settings. Each item is a binary response (yes or no) to the presence of symptoms ( 5 items), clinical signs ( 2 items) with total score 25 points. It was developed by Bennett G. (2001) and its reliability and validity tested by Bennett $M$, and Smith B $(2005)^{(19)}$. The S-LANSS has Cronbach $\alpha$ of 0.76 when completed unaided, rising to 0.81 when completed at interview, demonstrating a good level of internal consistency.

\section{Method}

- The official approvals from the competent authority.

- All studied patients were surveyed to identify those fulfilling the study criteria, then the researcher selected 30 patients randomly by ballot to participate in the study.

- Each patient included in the study groups interviewed individually to assess his phantom limb pain using S-LANSS tool to obtain basic data.

- The intervention: (range of motion exercise and massage sessions were executed five times daily for every patient for two weeks duration).

- Evaluation of phantom limb pain was implemented using S-LANSS tool.

- Data collection started from the 15 of March 2015 to the end of October 2015 .

\section{Ethical considerations:}

Informed consent of the patients was obtained after explanation of the purpose of the study. Confidentiality and patients' privacy were assured.

\section{Statistical Analysis}

Statistical analysis performed using Stata (version 13). P value less than 0.05 considered statistically significant. A chisquare test used to study the relationship between two categorical variables. An 
independent sample t-test used to compare the means of a normally distributed variable.

The Wilcoxon-Mann-Whitney test was used when the dependent variable was not normally distributed.

\section{Results}

Table (1) shows the sociodemographic characteristics of the studied patients; their age ranged from 20 to 60 years, patients aged 20-35 years constituted $53.34 \%$ of them, and the rest $33.33 \%$ and $13.33 \%$ were either $36-50$ years or more than 50 years respectively.

In relation to educational level the largest percent of the study subjects $46.67 \%$ have secondary education. Patients with primary education constituted $30 \%$ and those with higher education amounted $23.33 \%$

Concerning the patients' occupation the table shows that soldiers constituted $63.33 \%$ of the sample and worker patients amounted $26.67 \%$, the other types of occupation constituted $10 \%$ of studied sample.

Table (2) shows the injury characteristics of the studied patients; regarding the injury reason $60 \%$ of patients have injury because of military conflict, $26.67 \%$ of them in vehicle crashes and the machinery accidents constituted $13.33 \%$ of injury reasons.

In relation to injury site, the largest percentage of the study subjects $63.33 \%$ have lower limb injury, versus $36.67 \%$ have upper limb injury.

Concerning injury duration, the table shows that most of studied sample (46.67\%) have injury from 1-3 year and $33.33 \%$ of them have injury from less than one year, $20 \%$ for more than 3 years.

Table (3) shows the effect of exercises and massage on phantom limb pain. It appears from the table that the pain mean score of studied patients was $14 \pm 2.569$ before exercise and massage implementation decreased to $10 \pm 3.288$ after implementation with mean change percentage about $26 \pm 2.35 \%$; the difference was statistically significant $(\mathrm{P}=0.024)$.

Table (4) shows the relation between socio-demographic characteristics and changes in pain mean score after intervention. It appears from the table that the implementation of the exercise and massage, the age of the patients was not related to their phantom limb pain after the implementation. No statistical significant relation found $(\mathrm{P}=0.264)$; the same thing appear that the phantom limb pain score not affected by educational level of patients $(\mathrm{P}=0.366)$, while the implementation of the exercise and massage, the occupation of the patients was related to their phantom limb pain. A statistical significant relation was found $(\mathrm{P}=0.054)$.

Table (5) shows the relation between injury characteristics and changes in pain mean score after intervention. It appears from the table that the implementation of the exercise and massage; that the injury reason not related to the phantom limb pain after the implementation no statistical significant relation found $(\mathrm{P}=0.271)$; while the phantom limb pain was related to the injury site and injury duration, a statistical significant relation found $(\mathrm{P}=0.056)$, $(\mathrm{P}=0.049)$ respectively.

\section{Discussion}

It is generally recognized that in amputee rehabilitation, a multidisciplinary health team approach is required in order to address the individual's diverse needs. In today's medical and rehabilitation practice, that team usually consists of a medical doctor, nurse, physical therapist, occupational therapist and psychological support $^{(20,21)}$.

Recently we have learned much about the pathophysiology and management of phantom limb pain since it first described about five centuries ago. However, there is still no one unifying theory relative to the 
mechanism of it. Specific mechanism-based treatments are still evolving, and most treatments are based on recommendations for neuropathic pain. The evolution of the mechanistic hypothesis from body schema and neuropathic theories to the recently proposed role of mirror neurons in the mechanism of pain have added to our understanding of it $^{(22-24)}$.

Results of the present study revealed that the implemented range of motion exercises and massage improved significantly the patients' phantom limb pain. This improvement may attributed to the fixed schedule of the exercise program which motivated patients and changed upper, lower neurological signals sent to the pain center in patients' brain or pain threshold elevated with repetition of stimulation. Whereby the mean score percent after exercises, massage enhanced and the LANSS mean score decreased. This results supported by Ulger O (2009) and Tseng C (2007). They said in their studies; that after the exercises, the subjects felt less phantom limb pain due to the relaxation of the phantom limb. This indicates that exercises that alter muscle tension and position in the residual limb can influence the intensity of phantom pain ${ }^{(25,26)}$.

Often, amputees will experience pain symptoms in areas that are not directly associated with the amputation. These structures, referred to as compensatory structures, are the muscles and joints; that are required to perform new and/or additional functions due to the limitation or inability to perform them with the amputated limb. Such factors will further limit the amputees' functional abilities and should addressed early in order to prevent or relieve them; development of contractures in joints above the site of the amputations is a frequent occurrence ${ }^{(6,7,27)}$.

As contractures result in lost range of motion of the affected joint, reduction and prevention of contractures is very important in order to avoid complications such as poor prosthetic fit, gait deviations, inability to ambulate with a prosthetic all together, and development of pain in the effected muscles and joints. Thus, range of motion exercises can play an important role to improve patient capabilities and decrease phantom limb pain. In addition to its restrictive characteristics, scar tissue can have negative effect on the neighbouring tissues, resulting in stiffness, pain and limited range of motion. Furthermore, itching and sensitivity of scar tissue is very common, which besides being unpleasant, can reduce the amount of time a prosthetic tolerated (if it fits over the scar area) or reduced the range of motion of affected joints. Positive outcomes of scar tissue massage result in reduced tightness, stiffness, pain, itching, an increase in the range of motion of affected and surrounding joints and an overall improvement in movement quality ${ }^{(25-27)}$.

According to Munk N (2015) and Carrelli B (2015) who emphasized in their studies that the massage therapy recognized for its effect of increasing circulation, systemically and locally ${ }^{(28,29)}$. Good blood flow and appropriate tissue profusion is very important since it is the source of nutrients and waste elimination to and from all tissues. Many amputees report poor circulation of the affected limb, which results in a cold, and often time's painful residual limb. Winter can be a particularly difficult time as the cold weather reduces peripheral blood flow. Many amputees report it takes a number of hours, if at all, for the residual limb to return to a "normal" temperature and the burning pain to subside. Massage therapy and range of motion exercises can have a short-term or long-term effect in providing relief from the above symptoms. It is important to stress that relief for even a short period can have a very positive effect psychologically ${ }^{(29,30)}$.

Werner R (2014) in his study reported that the massage is effective at many levels of pain tissue level, cognitive level, and nerve level (pain gate) ${ }^{(30)}$. It is frequently sighted in rehabilitation textbooks for amputees that non-invasive techniques such 
as massage therapy increases sensory input from periphery (the limb) that may override the brains perception of pain, which may provide temporary or partial relief of the phantom pain. Massage treatment may consistent of applying massage directly to the amputated end (the stump), to the muscle and soft tissues above the amputated area (the residual limb) or to soft tissues at the proximal end of the effected limb. A more general massage approach may be appropriate as well, with the goal being to reduce stress and anxiety that are recognized as increasing the intensity or frequency of pain $^{(30)}$.

In addition, present study results revealed that a statistical significant relation between patients' occupation and pain mean score after massage and exercises was found. whereby the soldiers' mean score was better than other occupations after exercises and massage, this improvement may be due to the solider desire to heal quickly and most of soldiers were young or may they are more able to tolerate pain; while no significant relation with age and level of education was found.

Moreover, a statistical significant relation was noted between injury site and injury duration; this result may be related to that the lower limb pain mean score was more than upper before implementation, while the intensity of injury was more dangerous in lower limb. Duration of injury may affect the patient adaptation with pain this may lead to existence of more difference between patients who have the amputation recently and have phantom limb pain.

\section{Conclusion}

It can be concluded from the study that the limb massage and range of motion exercises improved significantly patients' phantom limb pain intensity.

\section{Recommendations}

- Incorporating range of motion exercise and limb massage into a pain management program is highly recommended due to the direct benefit in treatment of soft tissue dysfunction and circulatory problems.

- Also, it is highly recommended that an amputee receive limb massage in conjunction with the beginning prosthetic training and ongoing prosthetic use in order to prevent muscle strain, tightness and related pain symptoms that may develop due to the alterations in posture and biomechanics. 
Table (1): Distribution of the patients according to their socio-demographic characteristics

\begin{tabular}{||c|c|c|}
\hline Socio-demographic Characteristics & $\begin{array}{c}\text { No } \\
(\mathbf{n = 3 0})\end{array}$ & $\mathbf{\%}$ \\
\hline Age (in years) & & \\
- 20 - & 16 & 53.34 \\
- $36-$ & 10 & 33.33 \\
- $51>60$ & 4 & 13.33 \\
\hline Level of education & & \\
- Up to primary & 9 & 30 \\
- Secondary & 14 & 46.67 \\
- Higher education & 7 & 23.33 \\
\hline Occupation & & \\
- Soldier & 19 & 63.33 \\
- Worker & 8 & 26.67 \\
Other & 3 & 10 \\
\hline
\end{tabular}

Table (2): Distribution of the studied patients according to their injury characteristics

\begin{tabular}{|l|c|c||}
\hline Injury Characteristics & $\begin{array}{c}\text { No } \\
(\mathbf{n = 3 0})\end{array}$ & $\mathbf{\%}$ \\
\hline Injury reason & & \\
- Military conflict & 18 & 60 \\
- Vehicle crashes & 8 & 26.67 \\
- Machinery accidents & 4 & 13.33 \\
\hline Injury site & & \\
- Lower limb & 19 & 63.33 \\
- Upper limb & 11 & 36.67 \\
Injury duration & & \\
- Less than 1 year & 10 & 33.33 \\
- 1-3 years & 14 & 46.67 \\
- More than 3 years & 6 & 20 \\
\hline
\end{tabular}

Table (3): Effect of (ROM exercises, Massage) on phantom pain (LANSS) mean score

\begin{tabular}{||l|c|c|c|c||}
\hline & $\begin{array}{c}\text { Pain/LANSS } \\
\text { Mean score } \\
\text { (Before) }\end{array}$ & $\begin{array}{c}\text { Pain/LANSS } \\
\text { Mean score } \\
\text { (After) }\end{array}$ & $\begin{array}{c}\text { Mean percent } \\
\text { change }\end{array}$ & Significance \\
\hline $\begin{array}{l}\text { T. mean score } \\
25\end{array}$ & $14 \pm 2.569$ & $10 \pm 3.288$ & $26 \pm 2.35 \%$ & $P=0.024 *$ \\
\hline
\end{tabular}

*Significant value at $\mathrm{P} \leq 0.05$ 
Table (4): Relation between socio-demographic characteristics and changes in pain mean score after intervention

\begin{tabular}{|l|c|c|c||}
\hline Socio-demographic Characteristics & $\begin{array}{c}\text { Pain/LANSS } \\
\text { Mean score } \\
\text { (Before) }\end{array}$ & $\begin{array}{c}\text { Pain/LANSS } \\
\text { Mean score } \\
\text { (After) }\end{array}$ & Significance \\
\hline Age (in years) & & & \\
- $20-$ & $14 \pm 2.574$ & $9 \pm 1.988$ & \\
- 36- & $15 \pm 3.223$ & $9 \pm 1.559$ & $P=0.264$ \\
- 51- & $13 \pm 3.215$ & $10 \pm 3.236$ & \\
\hline Level of education & & & \\
- Preparatory & $14 \pm 2.569$ & $11 \pm 1.265$ & \\
- Secondary & $16 \pm 3.265$ & $12 \pm 2.445$ & $P=0.366$ \\
- Higher education & $14 \pm 3.216$ & $10 \pm 3.336$ & \\
\hline Occupation & & & \\
- Soldier & $17 \pm 2.523$ & $10 \pm 3.228$ & \\
- Worker & $13 \pm 3.465$ & $10 \pm 2.549$ & $P=0.054 *$ \\
- Other & $15 \pm 3.618$ & $11 \pm 1.586$ & \\
\hline
\end{tabular}

*Significant value at $\mathrm{P} \leq 0.05$

Table (5): Relation between injury characteristics and changes in pain mean score after intervention

\begin{tabular}{|l|c|c|c||}
\hline \hline Injury Characteristics & $\begin{array}{c}\text { Pain/LANSS } \\
\text { Mean score } \\
\text { (Before) }\end{array}$ & $\begin{array}{c}\text { Pain/LANSS } \\
\text { Mean score } \\
\text { (After) }\end{array}$ & Significance \\
\hline Injury reason & $18 \pm 2.569$ & $11 \pm 1.244$ & \\
- Military conflict & $15 \pm 3.265$ & $10 \pm 2.511$ & $P=0.271$ \\
- Vehicle crashes & $14 \pm 3.216$ & $10 \pm 3.266$ & \\
\hline Injury site & & & \\
- Lower limb & $19 \pm 2.569$ & $10 \pm 3.271$ & $P=0.056^{*}$ \\
- Upper limb & $14 \pm 3.265$ & $11 \pm 2.559$ & \\
Injury duration & & & \\
- Less than 1 year & $15 \pm 2.569$ & $9 \pm 2.188$ & \\
- More than 3 year & $13 \pm 3.265$ & $10 \pm 3.229$ & $P=0.049^{*}$ \\
\hline
\end{tabular}

*Significant value at $\mathrm{P} \leq 0.05$ 


\section{References}

1. Griffin A, Tsao J. A mechanism-based classification of phantom limb pain. Pain J. 4 June, 2014.

2. Giummarra M, Moseley L Phantom limb pain and bodily awareness: current concepts and future directions. Current Opinion in Anesthesiology 2011; 24: 524-31.

3. Ketz A. Pain Management in the Traumatic Amputee. Crit Care Nurs Clin N Am. 2008; 20: 51-57.

4. Hunter J. P. Katz J. and Davis K.D Stability of phantom limb phenomena after upper limb amputation: a longitudinal study. Neuroscience J. 2008; 156: 939-49.

5. Subedi B, Groosberg G. Phantom limb Pain Mechanisms and Treatment Approaches. Pain Research and Treatment. Accepted 1 July, 2011.

6. Nikolajsen L. Postamputation pain: studies on mechanisms. Dan Med J. 2012; 59(10): 4527.

7. Litwack k. Pain Management in Military Trauma. Crit Care Nurs 2015; 27: 235-46.

8. Hall G. Carroll D. Parry D, and McQuay J.H. Epidemiology and treatment of neuropathic pain: The UK primary care perspective. Pain $\mathbf{J}$ 2006;122: 156-62.

9. A sore spot: Central or peripheral generation of chronic neuropathic spontaneous pain. International Association for the Study of Pain. Published by Elsevier. Pain J. 2014; 155: 1189-91.

10. Week S, Anderson V and Tsao W.J. Phantom Limb Pain theories and therapies. The Neurologist 2010, v16, 5.
11. Vase L, Nikolajsen L, and Christensen B. Cognitive - emotional sensitization contributes to wind-up-like pain in phantom limb pain patients. Pain J. 2011; 152: 157-62.

12. Pain and phantom limbs. Published by The War Amps of Canada; The War Amps National Amputee Centre. Ottawa, Ontario 2013.

13. Malavera A, Carrillo S, and Carrillo S. Repetitive Transcranial Magnetic Stimulation for phantom limb pain in landmine victims. Journal of Pain. Accepted: May 2016.

14. Hsu E, Cohen S P. Post amputation pain: Epidemiology, mechanisms, and treatment. Journal of Pain Research. 2013; 6: 121-36.

15. Mortimer C M, Steedman W M. Patient information on phantom limb pain a focus group study of patient experiences, perception, and opinions. Health Education Research J .2002; 17: 291-304.

16. Fieldsen D, Wood S. Dealing with phantom limb pain after amputation. Nursing Times 2011; 7(1): 21-23.

17. Rafferty M, Bennett Britton T.M. Cross-sectional study of alteration of phantom limb pain with visceral stimulation in military personnel with amputation. JRRD 2015; 52: 441-48.

18. Ellis K. A review of amputation, phantom pain and nursing responsibilities. Br J Nurs 2002; 11(3): 155-7.

19. Bennett M, and Smith B, Torrance N, and Potter J. The S-LANSS Score for Identifying Pain of Predominantly Neuropathic Origin. The Journal of Pain 2005; 6:3,149-58.

20. Penn-Barwell G J. Outcomes in Lower Limb Amputation Following Trauma: A 
Systematic Review and Meta-Analysis. Injury, Int. J Care 2011; 42: 1474-79.

21. Halbert J, Crotty M, Cameron D. Evidence for the optimal management of acute and chronic phantom pain: systematic review. Clin J Pain 2002; 18(2): 84-92.

22. Clark J, Bowling F, Jepson F, and Rajbhandari S. Phantom limb pain after amputation in diabetic patients does not differ from that after amputation in nondiabetic patients. Pain J. 2013; 154 : 729-32.

23. Diers M, Christmann C, Koeppe C, and Flore H. Mirrored, imagined and executed movements differentially activate sensorimotor cortex in amputees with and without phantom limb pain. Pain J. 2010; 149: 296-304.

24. Knotkova H, Cruciani R. Current and future options for the management of phantom-limb pain. Journal of Pain Research 2012, 5: 39-49.

25. Ulger O, Topuz S, Bayramlar K. Effectiveness of phantom exercises for phantom limb pain: a pilot study. J Rehabil Med 2009; 41: 82-584.

26. Tseng C, Chen C. Effects of a range of motion exercise program. Journal of Advanced Nursing 2007; 57(2): 181-91

27. Tung M, Murphy I. Observation of limb movements reduces phantom limb pain in bilateral amputees. Annals of Clinical and Translational Neurology 2014; 1(9): 633-38.

28. Munk N, Mannheimer S. Novel prototype device combines massage therapy with components of mirror therapy to address phantom limb pain in lower-limb amputees. Journal of pain. 2015; 16: 4, 112.

29. Carrelli B. Massage and Chiropractic for phantom limb pain. 31 August, 2015. Available at: http://www.echiropractor.org.

30. Werner R. Massage and Bodywork Magazine for the visually impaired amputation adaptations. November 2014. 